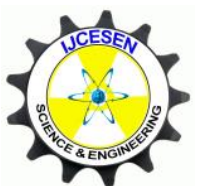

Copyright C IJCESEN
International Journal of Computational and

Experimental $\boldsymbol{S}$ cience and Engineering

(IJCESEN)

Vol. 5-No.1 (2019) pp. 10-18

http://dergipark.gov.tr/ijcesen

Research Article

\title{
Determination of The Cross Types to be used in a Trailer Chassis by Finite Element Method
}

\author{
Burak SEVIN $^{1} *$, Su Buse ŞAHIN ${ }^{2}$ \\ ${ }^{1}$ TIRSAN Solutions/P\&D Low-Bed \& Special Vehicles Business Unit, Sakarya, Turkey \\ ${ }^{2}$ TIRSAN Solutions/P\&D Tank \& Silo Business Unit, Sakarya, Turkey \\ * Corresponding Author : burak.sevin@kaessbohrer.com \\ ORCID: 0000-0001-9048-1204
}

\section{Article Info:}

DOI: $10.22399 /$ ijcesen.477613

Received : 1 November 2018

Accepted : 16 December 2018

\section{$\underline{\text { Keywords }}$}

Trailer

Cross Member

Finite Element Method

FEA

Transportation

\begin{abstract}
Cargo transportation is done by airway, railway, maritime line and highway according to time and cost criteria. Trailers are widely used in highway transportation which is one of these cargo transportation types. Depending on the amount and variety of loads, the trailers vary among themselves. In addition to this diversity, it is desirable that a trailer should be lightweight and at the same time strong as far as transport safety and transport costs are concerned. When all these factors come together, serious research and development activities are required from the design stage to the final stage of manufacturing. One of the R\&D phases is computer aided engineering analyzing. Without requiring material, labor and time, a design can be tested in virtual environment under certain boundary conditions before physical validation. Crosses, which are the one of the main carrier components in a trailer structure, between the longeron (main beam) and the frame, that exist perpendicular to these components, has been investigated in this study by taking into consideration of 1 $\mathrm{g}$ static loading, $0.8 \mathrm{~g}$ braking and torsion scenarios. In this study, the essential criteria are displacement and stress values of these crosses which have different geometries (cross-sections). Comparisons were made according to the results and in the light of these information, the finite element analysis results of the combination of the chosen crosses to be used in the production of the trailers were evaluated.
\end{abstract}

\section{Introduction}

In airway, railway, maritime line and highway transportation, highway transportation has a great importance in terms of its portion. According to Turkish Statistical Institute, $10 \%$ growth was achieved on the basis of exports realized in 2017 and the portion of highway transportation in this growth was $40 \%$. Compared to the previous year, highway transportation increased by $7 \%$ [1].

When developing technologies and innovation initiatives of companies are taken into consideration, TIRSAN Solutions is a leading brand that gives direction to Europe and the world with its various products and transportation solutions. Under this great responsibility, products are produced according to the comfort, safety and cost criteria brought by transportation. Achieving these criteria leads to serious $R \& D$ needs, and one of these needs is virtual tests which is known as simulations in other words, under the verification heading. Without requiring material, labor and time, a design can be tested in virtual environment under certain boundary conditions before physical validation.

Cross members, which are the one of the main carrier components in a trailer structure, between the longeron (main beam) and the frame, that exist perpendicular to these components, has been investigated in this study. The types of crosssections examined are omega, reversed omega, box profile, C-type and reversed U-profile. Similar to this study, M. J. Akhtar, in his master's thesis named "Development of Guidelines for the Selection of Structural Profiles to Achieve Optimized Flooring Structure", examined the types 
of cross members having different geometries [2]. These cross-sections were evaluated according to displacement and stress criteria and $1 \mathrm{~g}$ static loading, $0.8 \mathrm{~g}$ braking and torsion scenarios were applied [3]. In the braking scenario, certain calculations were made under the boundary conditions. During analyses, independent domains were used to ensure that the cross members did not affect each other and that an accurate assessment was made. Since cross-sections of these cross members are examined geometrically under certain loads and conditions, the thickness and length of these cross member types are the same. Comparisons were made according to the results and in the light of these information, the finite element analysis results of the combination of the chosen cross members to be used in the production of the trailers were evaluated via HyperWorks software [4].

\section{Methodology}

The method, Finite Element Analysis (FEA) which is developed by NASA, that helps to simulate mechanical components and systems to get information about failure, deformation and stresses under some various kind of loadings or conditions $[5,6,8,9]$. In fact, the life determination of the structures after this method was also carried out by fatigue analysis [14].

In mechanics, the static state can be defined as the state of a system in equilibrium under balanced forces and torques. A static load can be defined as a load that does not vary. If there is a slow change in load, the system or structure can be solved by static analysis; however, if this load varies rapidly, the response of the structure must be defined by dynamic analysis [7]. On the other hand, if an analysis is static, it means that it does not depend on time. In this type of analysis, the term linearity includes small deformations, steady values or directions of loads and constraints, materials considered as elastic [5]. The solver computes the stiffness matrix for a linear static analysis by using Hooke's Law (Eq.1). For this equation, $\mathrm{K}$, $\mathrm{x}$ and $\mathrm{f}$ indicates Global stiffness matrix, displacement and force respectively.

$$
K x=f
$$

\subsection{Definition of the Model}

HyperMesh software is one of the best tools for creating high-quality mathematical models, although ANSYS, Abaqus, etc. softwares have their own pre-processing tools. In this study, HyperMesh

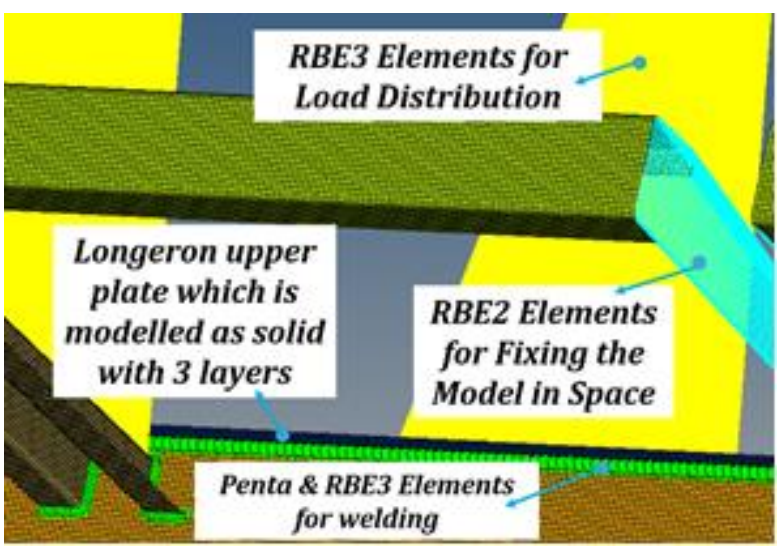

Figure 1. Element types in the Mathematical Model

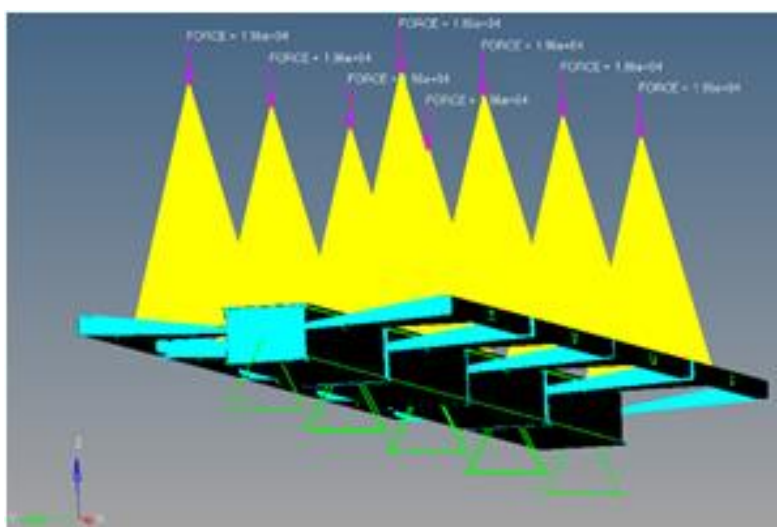

Figure 2. Capture of the Domain with Applied Forces

software was used as a pre-processing tool in constructing mathematical models [13]. Because of being in the same domain, for an independent comparison, cross members which have different cross-sections are located into frame and longeron parts separately. The average mesh size of the model is $5 \mathrm{~mm}$ and the components which have a thickness of $10 \mathrm{~mm}$ and above are modelled as solid and formed as 3 layers. Each cross member which is modelled as shell body has a thickness of $4 \mathrm{~mm}$, same height of $60 \mathrm{~mm}$ and same length of $989 \mathrm{~mm}$. Penta (mig) and RBE3 elements are used to model welding elements [10]. As a result of research on trailer platforms, a total of 40 tons cargo load can be carried by 20 cross members on average. So, each cross member has 2 tons of load on itself in this study. In the light of this information, forces at $19620 \mathrm{~N}$ are applied to each cross member via RBE3 elements. Load application points are $1600 \mathrm{~mm}$ above from the surface of the cross members. This $1600 \mathrm{~mm}$ measurement results from surveys and represents the average height of the center of gravity from ground of a caterpillar.

The use of this height in the analysis is important for providing a moment load to the structures in the 
braking and torsion scenarios. The mathematical model of these structures and the definition of the domain are illustrated in Figures 1 and 2 as analysis captures.

Element types and numbers that are used in the mathematical model are also specified in Table 1 and Table 2.

Table 1. Mesh Element Types and Numbers According to Structures in the Model

\begin{tabular}{|l|c|c|c|c|c|c|}
\hline Cross & \multicolumn{5}{|c|}{ ELEMENT TYPES \& NUMBERS } \\
\cline { 2 - 7 } $\begin{array}{l}\text { Member } \\
\text { Types Used } \\
\text { in Models }\end{array}$ & RBE2 & RBE3 & QUAD4 & PENTA & HEX8 & TOTAL \\
\hline Omega & 2 & 6113 & 132034 & 2017 & 287448 & 427614 \\
\hline $\begin{array}{l}\text { Reversed } \\
\text { Omega }\end{array}$ & 2 & 6098 & 132034 & 2014 & 287448 & 427596 \\
\hline Box Profile & 2 & 5654 & 133860 & 1870 & 279792 & 421178 \\
\hline C-Type & 2 & 5456 & 116016 & 1800 & 271440 & 394714 \\
\hline $\begin{array}{l}\text { Reversed } \\
\text { U-Profile }\end{array}$ & 3 & 5630 & 119580 & 1856 & 271440 & 398509 \\
\hline Combination & 2 & 7992 & 181138 & 2624 & 287448 & 479204 \\
\hline
\end{tabular}

Table 2. Section Views of Cross Members

\begin{tabular}{|l|c|l|c|}
\hline $\begin{array}{c}\text { Cross Member } \\
\text { Types Used in } \\
\text { Models }\end{array}$ & $\begin{array}{c}\text { Section } \\
\text { View }\end{array}$ & $\begin{array}{l}\text { Cross Member } \\
\text { Types Used in } \\
\text { Models }\end{array}$ & $\begin{array}{c}\text { Section } \\
\text { View }\end{array}$ \\
\hline Omega & $\square$ & C-Type & \\
\hline $\begin{array}{l}\text { Reversed } \\
\text { Omega }\end{array}$ & $\square$ & $\begin{array}{l}\text { Reversed } \\
\text { U-Profile }\end{array}$ & \\
\hline Box Profile & & Combination & $\square+$ \\
\hline
\end{tabular}

If the element types used in the mathematical model are defined, it can be specified that RBE2 and RBE3 are multi point constraint (MPC) rigid elements. A rigid element is used for node to node connection and it has infinite stiffness. It can transfer all the forces and moments that are acting on it. RBE2 Element has one independent node and multiple dependent nodes. On the other hand, RBE3 element has multiple independent nodes and a dependent node and also does not add any stiffness to the original structure. The most important difference between these two MPC rigid elements, RBE2 elements distribute the force and moment equally (homogeneously) and among all the connected nodes irrespective of position of force and moment application; whereas, RBE3 element is a constraint equation to distribute force and moment as per the distance $[15,16]$.

If the definition of element types is continued, the quad 4 elements used in the mathematical model, are 2D (1st order) quadrilateral elements with 4 nodes ordered in HyperMesh. There are two types of penta elements as penta6 and penta15, in which penta6 elements were used in this mathematical model. Penta6 elements are 3D (1st order) triangular prism pentahedra elements with 6 nodes ordered and Penta15 elements are 3D (2nd order) triangular prism pentahedra elements with 15 nodes ordered in HyperMesh. If it is defined where the penta elements (penta6) were used in this study, the welding elements (seam) used to connect components to each other, consist of penta6 and RBE3 elements. Finally, another element used in mathematical model is hex 8 element that hex 8 elements are 3D (1st order) hexahedra elements with 8 nodes ordered in HyperMesh [10].

Mentioned element types are shown in Table 3 with their visuals.

Table 3. Element Types with Their Visuals [10, 16]

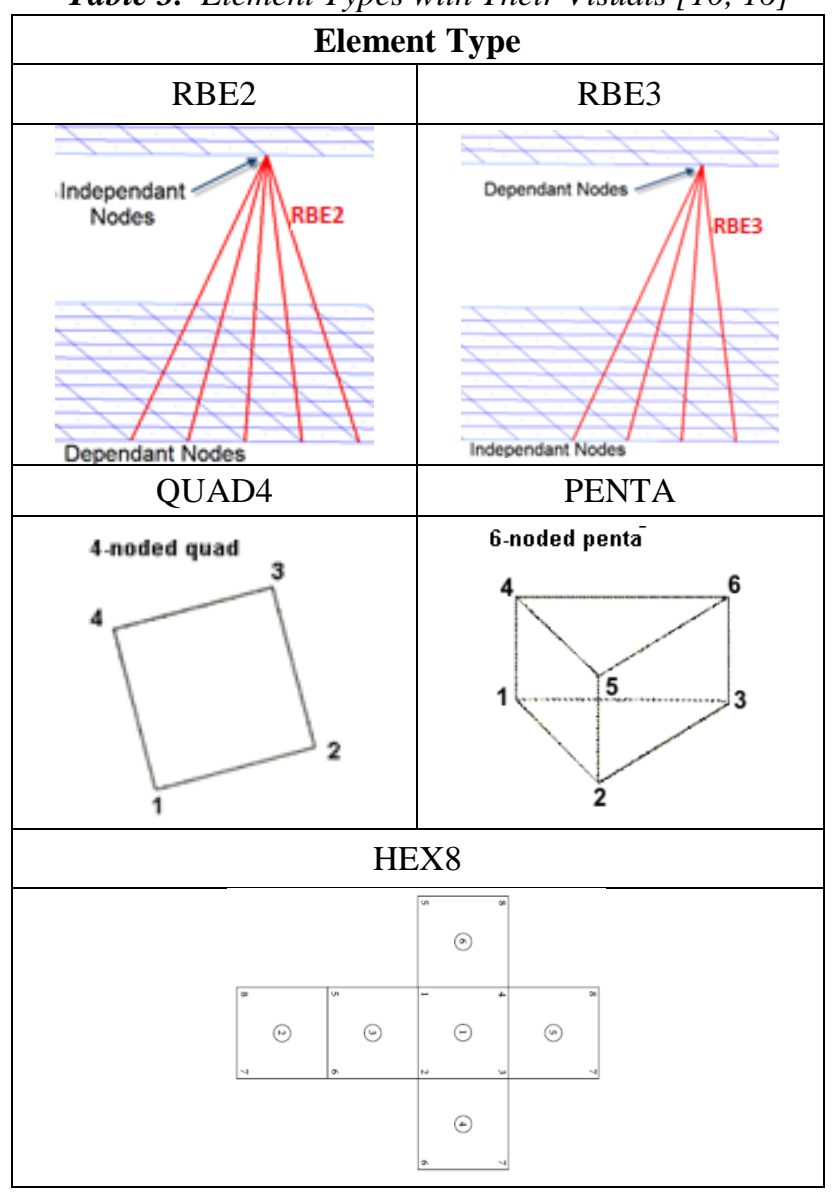

\subsection{Material Models}

The material of entire components in the mathematical model is steel. MAT1 term as card image (supported card) is used for this material on HyperMesh Platform. Supported card MAT1 defines the material properties for linear, temperature-independent, isotropic materials. The 
word "isotropic" consists of two words; these are "iso" and "tropic" which mean that "the same" and "directions" respectively. Properties of an isotropic material are independent from directions and axes. There are two independent constants that are modulus of elasticity (Young's modulus) (E) and Poisson's ratio $(v)$. It is valid for metals [11]. Properties of isotropic, orthotropic, anisotropic and laminates materials are specified in Table 4.

Table 4. Classification of Materials [11]

\begin{tabular}{|c|c|}
\hline ISOTROPIC & $\begin{array}{l}\text { - Iso: Same Tropic: Directions } \\
\text { - Properties independent of } \\
\text { direction/axes } \\
\text { - } 2 \text { Independent Constants (E, v) } \\
\text { - Metals }\end{array}$ \\
\hline ORTHOTROPIC & $\begin{array}{l}\text { - Ortho: Three } \\
\text { Tropic: Directions } \\
\text { - Different properties along } 3 \text { axes } \\
\text { - } 9 \text { independent constants } \\
\text { - Wood, Concrete, rolled metals }\end{array}$ \\
\hline ANISOTROPIC & $\begin{array}{l}\cdot \text { Different properties along } \\
\text { crystallographic plane } \\
\cdot 21 \text { independent constants } \\
\text { - All real life materials are } \\
\text { anisotropic only but we simplify } \\
\text { them into category of Isotropic } \\
\text { and Orthotropic } \\
\end{array}$ \\
\hline LAMINATES & $\begin{array}{l}- \text { Two or more materials bonded } \\
\text { together in layers. } \\
\text {-Simplest example is lamination } \\
\text { carried out on certificates, Identity } \\
\text { cards etc. } \\
\text {-Mainly used for space } \\
\text { applications and these days in } \\
\text { automobiles the trend is shifting } \\
\text { towards plastics and laminates } \\
\text { from metals. } \\
\end{array}$ \\
\hline
\end{tabular}

The properties of steel used in HyperMesh software is specified in the Table 5 .

Table 5. Mechanical Properties of St52 Steel [12]

\begin{tabular}{|c|c|c|}
\hline \multicolumn{2}{|c|}{ Material } & St52 Steel \\
\hline $\begin{array}{c}\mathbf{E} \\
\text { (Young Modulus) }\end{array}$ & $\mathrm{MPa}$ & 210000 \\
\hline $\begin{array}{c}\boldsymbol{n} \\
\text { (Poisson's ratio) }\end{array}$ & - & 0.3 \\
\hline $\begin{array}{c}\boldsymbol{\rho} \\
\text { (Material Density) }\end{array}$ & ton/ $/ \mathrm{mm}^{3}$ & $7.9 \times 10^{(-9)}$ \\
\hline Yield Strength & $\mathrm{MPa}$ & 355 \\
\hline
\end{tabular}

\subsection{Boundary Conditions}

In the solution of a problem, the suitability of the boundary conditions is very important for the correct solution of the problem. At this point, the definitions that are verification and validation, come into play. To briefly describe these two concepts; verification can be specified as an analysis is performed correctly. On the other hand, verification can also be described as the process of checking that the software or method meets the specification. Validation is to check the results or to tend to a problem correctly [17].

As it is known, before the production of a design, service loads should be determined precisely. In the earlier stages of suspension and chassis designs, wheel loads were generally not obvious or attempted to be measured by prototypes. For this reason, instead of obtaining actual loads, the standard load scenarios which are very close to these loads are foreseen and started to be used. Manoeuvres determining these standard load scenarios, are assumed to be quasi-static and these loads are applied in the analysis scenarios in order to control the strength of the structure [18].

The $1 \mathrm{~g}$ static loading scenario is the most basic scenario that satisfies the expected reaction forces and shows the status of strength of the structure. In fact, it can be said that this scenario is a litmuspaper that shows the state of strength of the structure under a given payload or in unloaded condition.

When the sources related to load scenarios are examined, the acceleration value used for the braking scenario varies between 0.7 and $1 \mathrm{~g}$ for automotive industry [18]. For this study, $0.8 \mathrm{~g}$ acceleration is used for braking scenario and the force calculations that are explained in detail in the relevant section are made according to this value.

Separately from the aforementioned quasi-static cases, torsion scenarios are also applied to the structure. In general, 1 to 3 degree torsion simulations are performed for stiffness and strength controls of the trailer chassis. This scenario also shows not only the status of structures, but also the status of the welding elements that connect the structures to each other.

These scenarios were examined under three main headings for this study: $1 \mathrm{~g}$ static loading, $0.8 \mathrm{~g}$ braking and 3 degree torsion.

\subsubsection{1 g Static Loading Scenario}

Omega, reversed omega, box profile and C-type cross members are compared in this scenario. Frames and longerons are fixed for all translational and rotational DOFs at their edges. $1 \mathrm{~g}$ gravitational acceleration is applied to the entire domain. There 
are two cross members for each structure at total as one for right and left side. The forces of $19620 \mathrm{~N}$, corresponding to 2 tons, were applied to the crosses via RBE3 elements. Benchmark criteria are stress and displacement values.

\subsubsection{8 g Braking Scenario}

As an additional information, according to first analysis (1 g static loading) results, C-type cross member is eliminated and instead of it, reversed Uprofile is examined. Hence, omega, reversed omega, box profile and reversed U-profile cross members are compared. Structures are fixed at all DOFs from the edge of frames. Structures extend through the x-coordinate in domain; so, one side of the longeron is fixed at other DOFs, except for the direction of braking. Translational DOF is free for this coordinate and from the opposite edge of longeron is pulled by calculated braking force (force application point is free for all DOFs). For the braking force, weights of groups which have four different cross member types were calculated via HyperMesh software. Total number of cross members for each group is 6 ( 3 for right-side and 3 for left-side) unlike models used in $1 \mathrm{~g}$ static loading scenario. Therefore, the total mass (M) for each group is calculated as Eq. 2:

$$
M=(2 \text { tons } x 6 \text { crosses })+\left(m_{\text {model }}\right)
$$

For the braking force, it can be calculated as Eq. 3:

$$
F_{\text {Braking }}=0.8 g \times M
$$

The forces for braking varies depending on the weight of each group. On the other hand, the gravitational acceleration is active.

The screenshot is shown in Figure 3, which describes the restriction of the structures to the specified degrees of freedom and the braking forces that are applied to each structure via RBE2 elements and calculated individually.

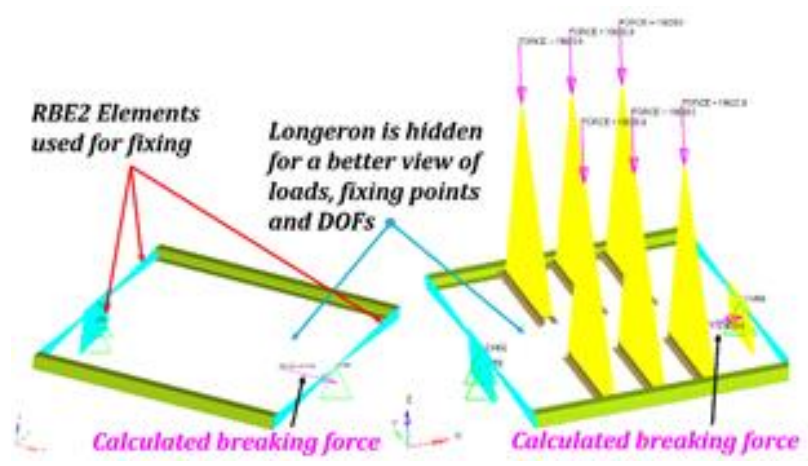

Figure 3. Constraints on DOFs and Applied Forces via RBE3 Elements

\subsubsection{Degree Torsion Scenario}

For each group of structures, all 6 DOFs are fixed but for one edge of structures the 4th DOF (rotational DOF @x coordinate) has a value of 3 degrees to perform torsional scenario. As in other scenarios, benchmark criteria are stress and displacement values. The screenshot of the torsion scenario is shown in Figure 4 with a 3-times deformation factor.

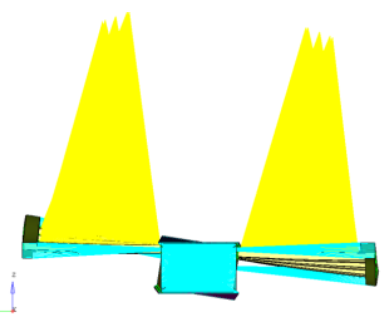

Figure 4. $3^{\circ}$ Torsion Effect - 3x Deformation Factor

\section{Linear Static Analysis Results}

The screenshots of these three scenarios (HyperView) including the displacement and stress values are shown in Figure 5, 6, 7.1 and 7.2; and the values containing all these analysis results are examined in Table 6. The legend was set to 355 $\mathrm{MPa}$ as the yield stress value of St52 steel [12].

Table 6. Benchmark of the Cross Member Types

\begin{tabular}{|c|c|c|c|c|}
\hline $\begin{array}{l}\text { Cross } \\
\text { Types }\end{array}$ & $\begin{array}{l}\text { Analysis } \\
\text { Scenarios }\end{array}$ & $\begin{array}{c}\text { Max Stress } \\
\text { [MPa] } \\
\text { (On Welding } \\
\text { Region) }\end{array}$ & $\begin{array}{c}\text { Max Stress } \\
\text { [MPa] } \\
\text { Exceptfor } \\
\text { Welding } \\
\text { Region) }\end{array}$ & $\begin{array}{c}\text { Max } \\
\text { Displacement } \\
{[\mathrm{mm}]}\end{array}$ \\
\hline \multirow{3}{*}{ Omega } & $\begin{array}{l}\text { Static } 1 \mathrm{~g} \\
\text { Loading }\end{array}$ & 147.8 & $\mathrm{X}$ & 2.857 \\
\hline & $\begin{array}{l}\text { Braking } \\
\text { Effect }\end{array}$ & 1226.3 & 649.2 & 14.707 \\
\hline & $\begin{array}{c}\text { Torsion } \\
\text { Effect }\end{array}$ & 468 & 316 & 55.345 \\
\hline \multirow{3}{*}{$\begin{array}{c}\text { Reversed } \\
\text { Omega }\end{array}$} & $\begin{array}{l}\text { Static } 1 \mathrm{~g} \\
\text { L oading }\end{array}$ & 236.9 & $\mathrm{X}$ & 3.909 \\
\hline & $\begin{array}{l}\text { Braking } \\
\text { Effect }\end{array}$ & 1268.7 & 912.3 & 10.469 \\
\hline & $\begin{array}{c}\text { Torsion } \\
\text { Effect }\end{array}$ & 573.3 & 429 & 55.458 \\
\hline \multirow{3}{*}{$\begin{array}{c}\text { Box } \\
\text { Profile }\end{array}$} & $\begin{array}{l}\text { Static } 1 \mathrm{~g} \\
\text { L oading }\end{array}$ & 111.8 & $\mathrm{X}$ & 2.332 \\
\hline & $\begin{array}{l}\text { Braking } \\
\text { Effect }\end{array}$ & 1788.2 & 380.4 & 10.616 \\
\hline & $\begin{array}{l}\text { Torsion } \\
\text { Effect }\end{array}$ & 909.4 & 480 & 54.828 \\
\hline \multirow{3}{*}{$\begin{array}{l}\text { Reversed } \\
\text { U-Profile }\end{array}$} & $\begin{array}{l}\text { Static } 1 \mathrm{~g} \\
\text { Loading }\end{array}$ & $\mathrm{X}$ & $\mathrm{X}$ & $\mathrm{X}$ \\
\hline & $\begin{array}{l}\text { Braking } \\
\text { Effect }\end{array}$ & $\underline{1242.5}$ & 738.5 & 23.697 \\
\hline & $\begin{array}{l}\text { Torsion } \\
\text { Effect }\end{array}$ & 609.5 & $\underline{408}$ & 57.431 \\
\hline $\begin{array}{c}\text { C-Type } \\
\text { Cross }\end{array}$ & $\begin{array}{l}\text { Static 1g } \\
\text { Loading }\end{array}$ & 923 & $\mathrm{X}$ & 14.562 \\
\hline
\end{tabular}
According to Stress and Displacement Values 


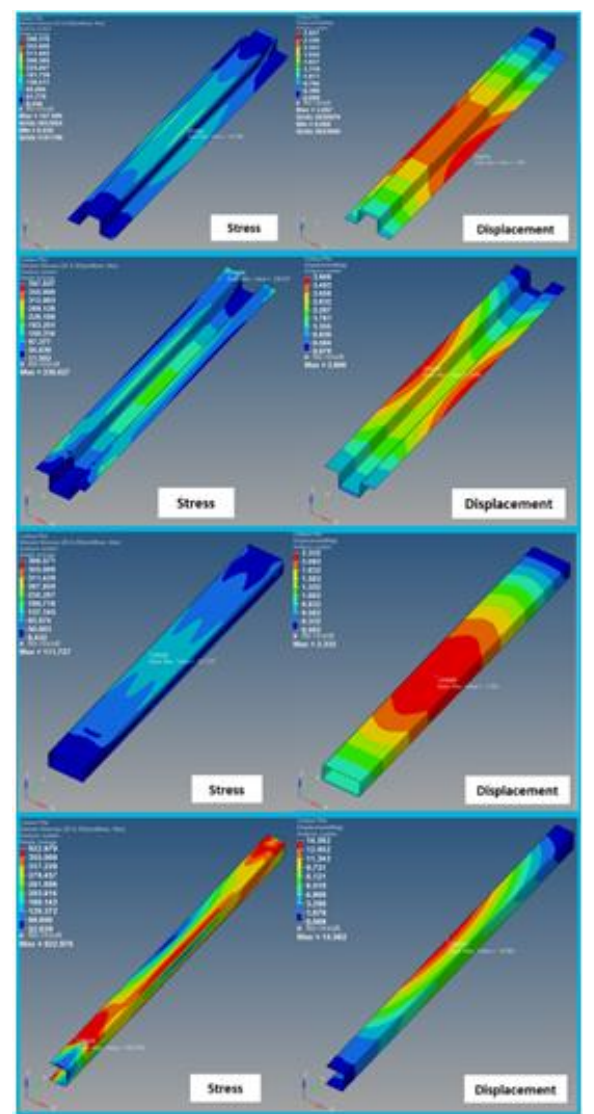

Figure 5. Results of $1 \mathrm{~g}$ Static Loading Scenario of the Cross Member Types

According to this benchmark, the best values and the obtained values that come after the best are indicated in this table. Considering these values, "the combination of omega and box profile cross member types" will be subjected to braking and torsion scenarios.

In consequence of braking scenario, the maximum stress value (on welding region), the maximum stress value except for welding region and the maximum displacement value are $1956.81 \mathrm{MPa}$, $575.74 \mathrm{MPa}$ and $12.793 \mathrm{~mm}$ respectively for the combination and these are illustrated in Figure 8.

In consequence of $3^{\circ}$ torsion scenario, the maximum stress value (on welding region), the maximum stress value except for welding region and the maximum displacement value are 930.27 $\mathrm{MPa}, 504.214 \mathrm{MPa}$ and $55.171 \mathrm{~mm}$ respectively for the combination and these are illustrated in Figure 9.

\section{Conclusion}

The mathematical model formed from the combination of omega and box profile type cross members was subjected to braking and torsion scenarios.
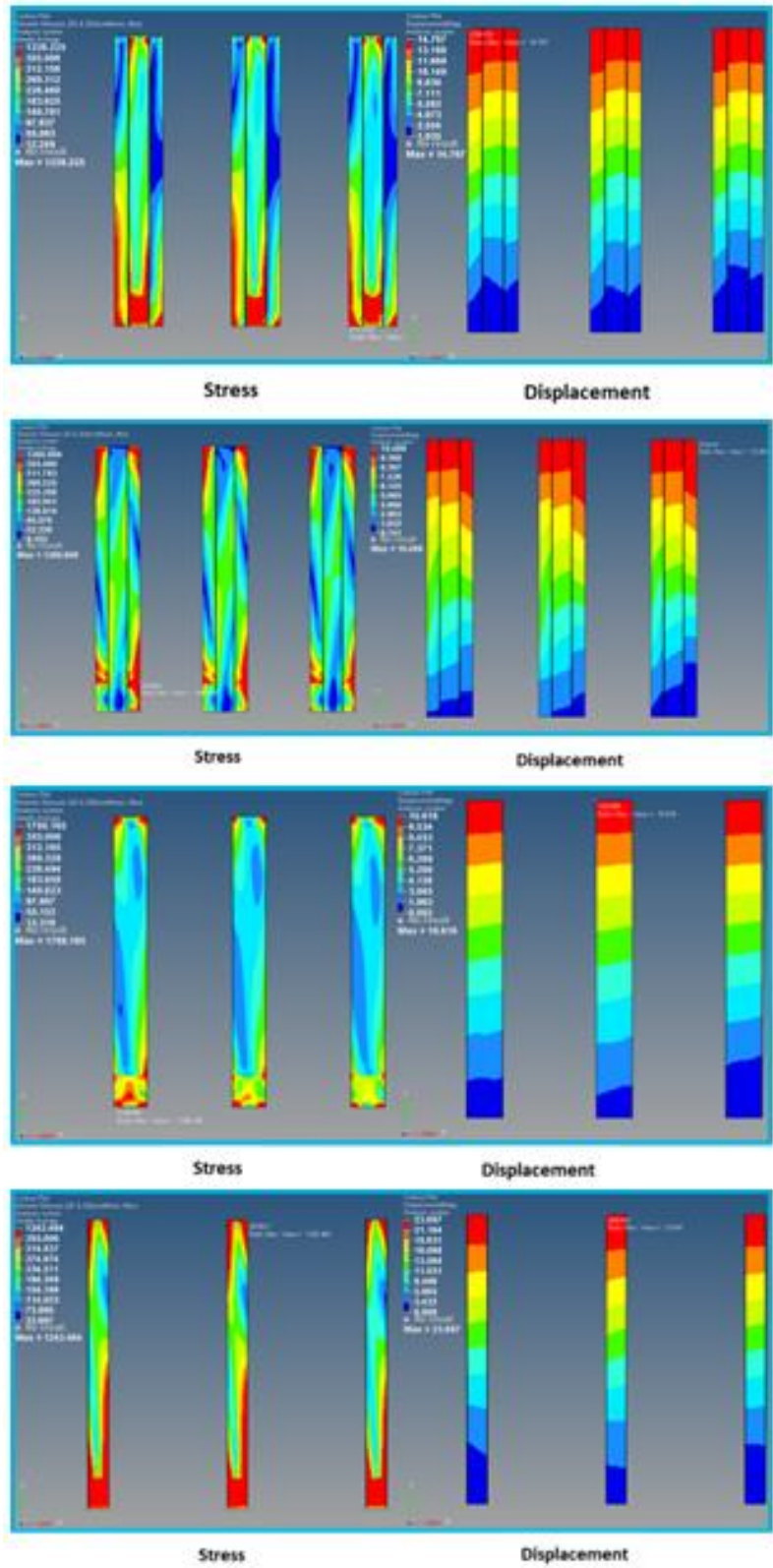

Figure 6. Results of $0.8 \mathrm{~g}$ Braking Scenario of the Cross Member Types

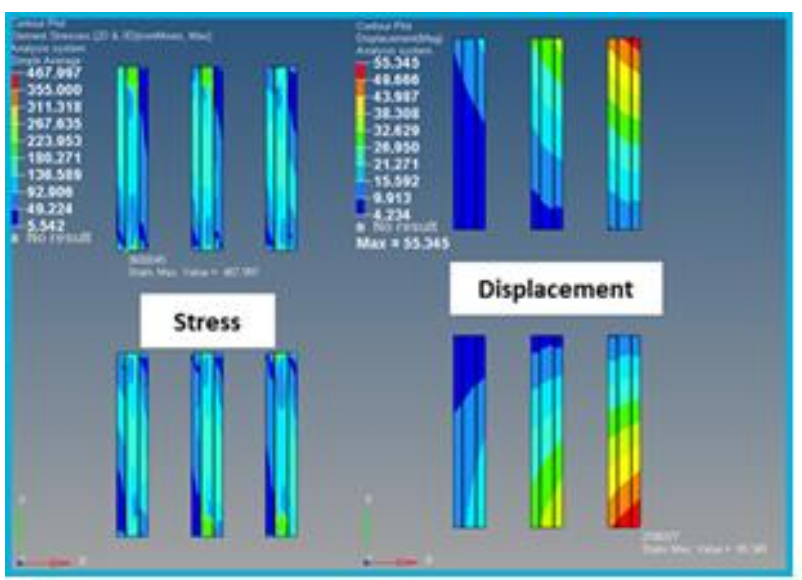

Figure 7.1. Results of $3^{\circ}$ Torsion Scenario of the Cross Member Types 


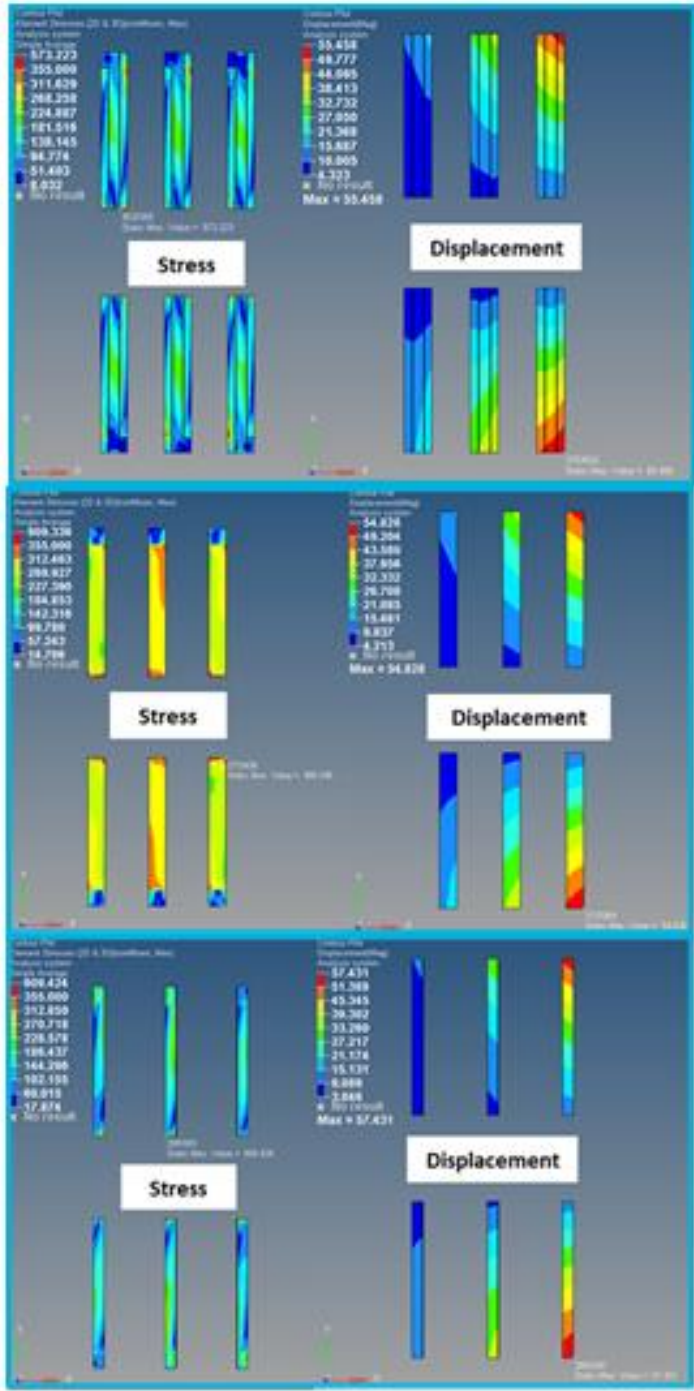

Figure 7.2. Results of $3^{\circ}$ Torsion Scenario of the Cross Member Types

Table 7. Results of the Benchmark

\begin{tabular}{|c|c|c|c|c|}
\hline Cross Types & $\begin{array}{c}\text { Analysis } \\
\text { Scenarios }\end{array}$ & \begin{tabular}{|c} 
Max Stress \\
{$[$ MPa $]$} \\
(On \\
Welding \\
Region)
\end{tabular} & $\begin{array}{c}\text { Max Stress } \\
{[\text { MPa }]} \\
\text { (Except for } \\
\text { Welding } \\
\text { Region })\end{array}$ & $\begin{array}{c}\text { Max } \\
\text { Displacement } \\
{[\mathrm{mm}]}\end{array}$ \\
\hline \multirow{3}{*}{ Omega } & $\begin{array}{l}\text { Static } 1 \mathrm{~g} \\
\text { Loading }\end{array}$ & 147.8 & X & 2.857 \\
\hline & $\begin{array}{c}\text { Braking } \\
\text { Effect }\end{array}$ & $\begin{array}{l}* i \\
1226.3 \\
\end{array}$ & $*$ ii 649.2 & $* i V \quad 14.707$ \\
\hline & $\begin{array}{l}\text { Torsion } \\
\text { Effect }\end{array}$ & $* i \quad 468$ & * iii 316 & $* \dot{I V} 55.345$ \\
\hline \multirow{3}{*}{ Box Profile } & $\begin{array}{l}\text { Static 1g } \\
\text { Loading }\end{array}$ & 111.8 & $\mathrm{X}$ & 2.332 \\
\hline & $\begin{array}{l}\text { Braking } \\
\text { Effect }\end{array}$ & $* i 1788.2$ & 380.4 & 10.616 \\
\hline & $\begin{array}{l}\text { Torsion } \\
\text { Effect }\end{array}$ & $* i \quad 909.4$ & $* \dddot{a i i} 480$ & 54.828 \\
\hline \multirow{3}{*}{ Combination } & $\begin{array}{l}\text { Static 1g } \\
\text { Loading }\end{array}$ & $* v \quad$ N/A & $* V \quad$ N/A & $* V \quad$ N/A \\
\hline & $\begin{array}{l}\text { Braking } \\
\text { Effect }\end{array}$ & $\begin{array}{l}* i \\
1956.9 \\
\end{array}$ & $* \ddot{i} \quad 575.8$ & $*$ iV 12.793 \\
\hline & $\begin{array}{l}\text { Torsion } \\
\text { Effect }\end{array}$ & $* i \quad 930.3$ & $*$ iii 504.3 & $* \dot{I V} 55.171$ \\
\hline
\end{tabular}

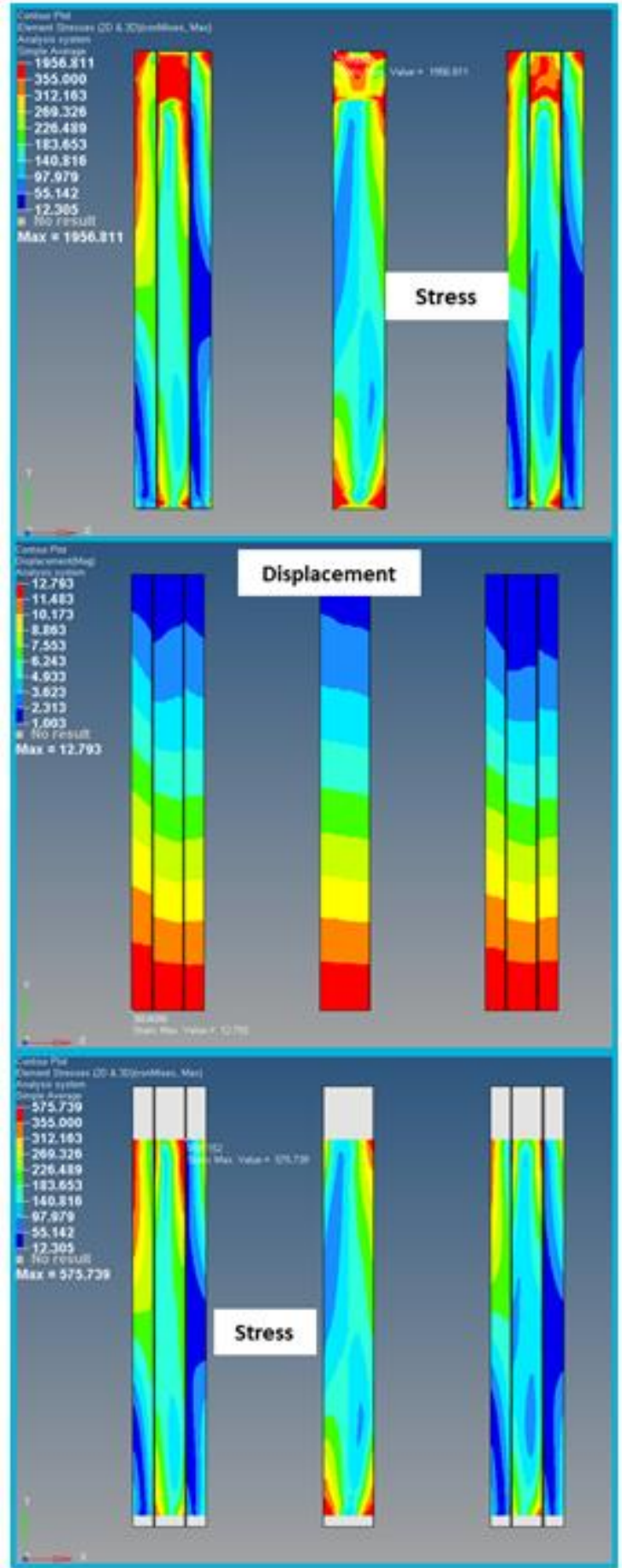

Figure 8. Results of $0.8 \mathrm{~g}$ Braking Scenario of the Combination

In this study, the maximum stress and displacement values on the regions where belong to components and near the welding elements were investigated. Finally, in the generated table (Table 7), models constructed from only omega type cross members and only box-profile type cross members were compared with this combination mathematical model separately. 

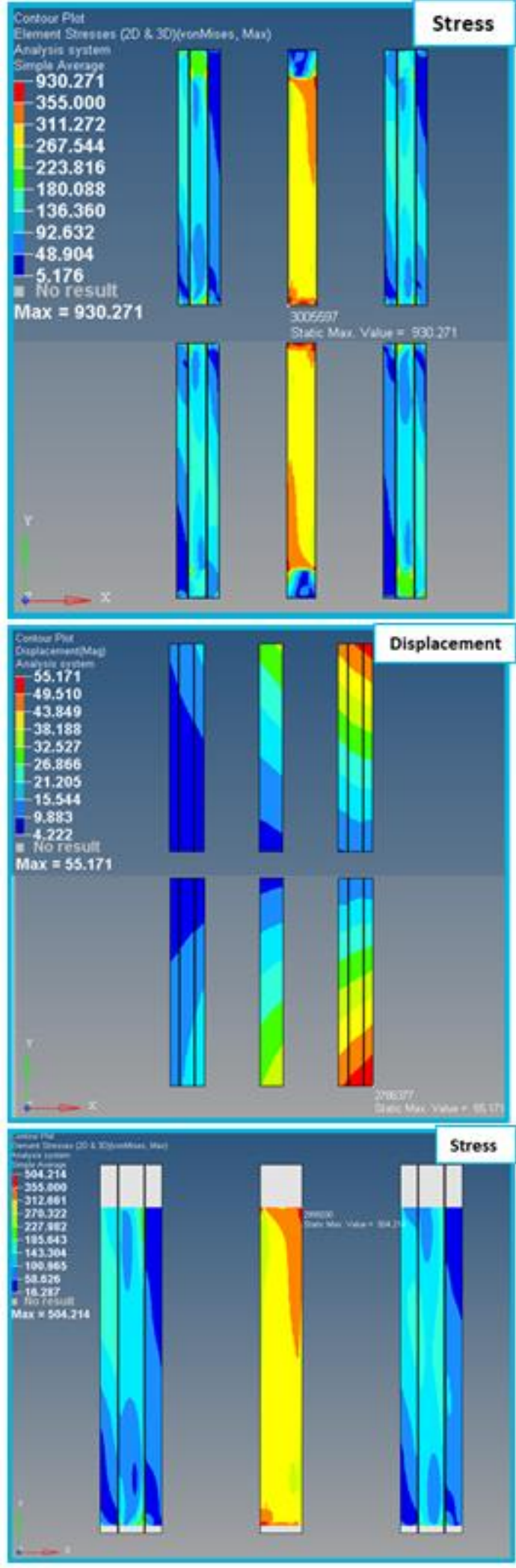

Figure 9. Results of $3^{\circ}$ Torsion Scenario of the Combination

When the results on Table 7 are examined for the combination model:

$i$. Maximum stress values on welding regions are increased for both braking and torsion scenarios. ii. On regions where the welding zone is not included, the stress value in the braking scenario is reduced in comparison to when the omega type cross member is used alone.

iii. Increment of stress values is observed in the torsion scenario in comparison to both omega and box-profile type cross members.

$i v$. According to the braking and torsion scenarios, the displacement values are decreased in compliance with the model in which omega is used alone.

v. Abbreviation of "Not available (N/A)" term in Table 7 means that $1 \mathrm{~g}$ static loading scenario is not performed for the combination of cross member types. When the static loading scenarios of $1 \mathrm{~g}$ were examined, the stress values that obtained were below the yield stress value of St52 steel which is the material of the components. Thus, the braking and torsion scenarios are used for decision.

The mass of the omega type cross member and boxprofile type cross member in the mathematical model were measured as $8.55 \mathrm{~kg}$ and $10.26 \mathrm{~kg}$, respectively. The models where box profile type cross members are used provide the best results; however, when the entire trailer chassis is constructed by using only this cross member type, approximately it will bring an extra $20 \%$ weight to the structure instead of the omega type cross member is used alone. Lightness is an important criterion for the construction of trailer bodies, it is a heavy solution to use only box profiles based on this results. Thus, to be competitive and to achieve optimum weight on the chassis, using both omega and box profile type as a combination is a logical solution.

\section{References}

[1] Uluslararası Nakliyeciler Derneği, Statistics (30.10.2018), https://www.und.org.tr/tr/19744/Istatistikler

[2] Akhtar, M. J. (2017), Master Thesis, Aalto University, Development of Guidelines for the Selection of Structural Profiles to Achieve Optimized Flooring Structure.

[3] Shinde, D., Kalita, K., "FE Analysis of Knuckle Joint Pin Used in Tractor Trailer." ARPN Journal of Engineering and Applied Sciences 10 (2015) 2227-2232.

[4] Sane, S.S., Jadhav, G., Anandaraj, H., "Stress Analysis of Light Commercial Vehicle Chassis by FEM", Piaggio Vehicle Pvt. Ltd, Pune, India (1955). 
[5] FEA for All, Linear Static Analysis (18.10.2018), http://feaforall.com/linear-static-analysis-fea/

[6] Esener, E., Ercan, S., Frrat, M., "Determination of the Fatigue Behavior of a Wheel Rim Using Finite Element Analysis", 4th Int. Conf. on Comp. and Exp. Scien. and Eng. (ICCESEN-2017) , Antalya-Turkey pp. 617-619 (2017) DOI: 10.12693/APhysPolA.132.617

[7] Altair OptiStruct Linear Analysis 13.0 Manual

[8] Karaçalı, Ö., "Computational Material Analysis of Structural and Hemodynamic Model of Coronary Stent by CFD/FEA in Computer Aided Mechanical Engineering Approach", 3rd Int. Conf. on Comp. and Exp. Scien. and Eng. (ICCESEN-2016) Antalya-Turkey pp. 249-251(2016). DOI: 10.12693/APhysPolA.130.249

[9] Karaçalı, Ö., "Computational Engineering Analysis of Low-Cycle Loading for AMF-Active Micro Forceps 316 L-Stainless Steel Material by Finite Element Method", 2nd Int. Conf. on Comp. and Exp. Scien. and Eng. (ICCESEN-2015) AntalyaTurkey pp.B-40-42 (2015). DOI:10.12693/APhysPolA.128.B-40

[10] Altair HyperWorks 14.0 Manual

[11] Altair University, Material and Property Information

http://altairuniversity.com/wpcontent/uploads/2014/02/matprop1.pdf

[12] TS 2162 EN 10025, Table 5, Turkish Standards Institution, 1996

[13] Özer, H., Can, Y., Yazıc1, M., "Investigation of the Crash Boxes Light Weighting with Syntactic Foams by the Finite Element Analysis", 4th Int. Conf. on Comp. and Exp. Scien. and Eng. (ICCESEN-2017) , Antalya-Turkey pp. 734-737 (2017). DOI: 10.12693/APhysPolA.132.734

[14] Özsoy M., Pehlivan K., Fırat M., Özsoy N., Uçar V., "Structural Strength and Fatigue Life Calculation of Y32 Bogie Frame by Finite Element Method", 2nd Int. Conf. on Comp. and Exp. Scien. and Eng. (ICCESEN-2015) Antalya-Turkey pp.B327-329 (2015). B-327-329. DOI: 10.12693/APhysPolA.128.B-327

[15] RBE2 vs RBE3 vs RBOBY (12.11.2018), https://forum.altair.com/topic/18187-rbe2-vs-rbe3vs-rbody/

[16] Altair University, 1D Elements and Connectors (12.11.2018), $\quad \underline{\text { https://altairuniversity.com/wp- }}$ content/uploads/2012/04/HM_1D_Extract.pdf

[17] CAE ASSOCIATES, Engineering Advantage, Is Your FEA Process Verified and Validated? (14.11.2018), https://caeai.com/blog/your-feaprocess-verified-validated

[18] Heißing, B., Ersoy M., Chassis Handbook, Springer Fachmedien Wiesbaden GmbH (2011), pp. 467-468 